\title{
Exploration of the role and effect of robot course in the training of application ability
}

\author{
Li Wang ${ }^{1}$, Enguang Zhang ${ }^{1}$ \\ ${ }^{1}$ Zhuhai College of Jilin University, Zhuhai, China
}

\begin{abstract}
Combined with the application-oriented independent colleges to build a college of robotics industry, and many years of experience in setting up robot courses, it is proposed that robot courses play an important role in the cultivation of students' application ability, which can promote students' ability to obtain comprehensive information actively, improve their practical ability, stimulate their innovation ability,and train students' engineering design thinking.It is an effective carrier of cultivating students' application ability. And the practice effect is remarkable, many excellent student robot works have emerged, which provides the basis for further improving the teaching quality and teaching reform.
\end{abstract}

\section{Introduction}

"Made in China 2025" clearly puts forward intelligent manufacturing as the main direction of deep integration with information and industrialization[1]. Robot is a typical carrier of mechanics, electronics, computer technology, artificial intelligence and other disciplines [2]. Industrial robot technology serves the intelligent innovation field of national equipment manufacturing industry, and the development of intelligent manufacturing must be inseparable from the development of robot technology. With the application of robots more and more widely, the society needs more and more talents who master robot application and maintenance technology.

Zhuhai College of Jilin University, as one of the first batch of "Guangdong ordinary undergraduate transformation Pilot Universities", shoulders the mission of innovation driving force of local economic and social development. Transition to a High Level Applied University is the focus of the thirteenth Five-Year Plan construction of Zhuhai College. It is the fundamental goal of the school to train compound applied talents who serve the production, construction, management and service of enterprises. The school has not only set up robot courses for many years, but also cooperated with Zhuhai ABB company to build a robot industry college mainly relying on mechanical and electronic engineering. The mechanical and electronic engineering specialty has also been awarded the school's characteristic specialty. These are timely measures to meet the needs of talent training.
Robot is a high-end mechatronics product, which can arouse students' learning enthusiasm. Robotics is an interdisciplinary subject, involving not only the mechanical knowledge of robot itself, but also electronics, control, computer, artificial intelligence, biology, psychology and so on. The opening of robot course can promote students' ability to obtain comprehensive information actively, improve students' practical ability, and stimulate students' innovation and invention ability. It is an effective carrier for cultivating students' application ability. Intelligent manufacturing urgently needs colleges and universities to cultivate a large number of robot engineering and technical personnel. Robot course has important educational value in the cultivation of diversified and applied engineering and technical talents. The upgrading between the emerging industry and the traditional industry has become the main direction of industrial robot application in the future. The bottleneck we are facing is not the shortage of technology, but the serious shortage of technical personnel in industrial machinery.

\section{Current situation of the courses}

Robot is a typical mechatronics product. Robot course is a rare course specially offered for a kind of equipment in colleges and universities. Robotics is an interdisciplinary subject involving machinery, electronics, computer, artificial intelligence, biology, etc[4]. Robot technology not only requires students to master basic knowledge and professional knowledge, but also needs to learn to flexibly apply comprehensive knowledge and interdisciplinary knowledge for fusion analysis and design [5].

\footnotetext{
*Corresponding author's e-mail: 24681876@qq.com
} 
At present, the main problems existing in the teaching of robot course in colleges and universities include: more theories but less practice in the teaching process; more knowledge imparting but less ability training; the teaching content is aging and lagging, and the teaching focus is still on the mechanical arm[5].The teaching content is boring, the teaching mode is single, and the experimental practice link is deficient, which seriously affects students' learning enthusiasm and is not conducive to the cultivation of applied talents.

\section{Teaching method reform}

Zhuhai College of Jilin University offers robot courses such as "industrial robot foundation", "Introduction to robot engineering" and "robot programming technology" in mechanical and mechanical electronic engineering specialty. Robot industry college cooperates with ABB company, which is one of the four major robot brands. A large number of ABB industrial robots and electromechanical integration production lines containing robots are purchased, which provides sufficient guarantee for students' practical teaching. Combined with modern teaching means and methods, teaching reform is actively carried out from the aspects of teaching concept, teaching method, teaching content and teaching mode, so as to integrate "theory--- virtual simulation ---practice--application" to effectively cultivate students' robot theoretical knowledge, engineering practice and innovative application ability. The course strengthens the popularization of robot theoretical knowledge through classroom theoretical knowledge teaching and special lectures, so that students can construct the knowledge framework of robot system. In the process of theory teaching, teaching methods are flexible and diverse, including not only theoretical introduction, but also application examples of robot engineering and video teaching of advanced typical robot and its technology. Various forms such as heuristic teaching, problem-based teaching and flipped classroom are adopted to make the course teaching intuitive, easy to understand, enlighten innovation and stimulate interest of students. Theoretical teaching can make students familiar with robot technology and its development, basically master the mechanism design of robots, especially industrial robots, and have an entry-level understanding of the basic knowledge of robot kinematics analysis, control and system design, so as to cultivate students' engineering technology ability of robot design and application.

The introduction of virtual simulation technology into robot teaching process is one of the main characteristics of robot teaching in our university. The virtual simulation process is a bridge between theoretical teaching and practical teaching. Through virtual simulation, students' understanding and mastery of theoretical knowledge can be deepened, and the process of robot entity operation can be previewed. Virtual simulation adopts the means of easy to use, graphic and motion simulation, which is convenient for students to modify in the process of innovation. It has the advantages of low cost, strong universality and easy implementation. It can solve the problem of hardware equipment shortage caused by a large number of students participating in practice at the same time.

\section{Course function and effect}

Robot related courses have played a positive role in the cultivation of students' application ability, and achieved good training results.

\subsection{Promoting students' ability to obtain comprehensive information on their own initiative}

During the teaching process of this course, students will be assigned the task of literature retrieval according to special topics. On the basis of broadening students' understanding of the latest frontier technology and development trend of robots, it is more important to promote students' ability to actively obtain comprehensive information and conduct knowledge screening and sorting.

\subsection{Improve students' practical ability}

The school continuously enriches the robot practice teaching equipment and resources. In view of the different levels and interests of students, a variety of experimental practice courses with different levels are designed, including primary experiment, comprehensive experiment, professional practice, graduation design, etc., which greatly improves the students' practical ability and integrates theory with practice teaching. This kind of teaching design and mode has also achieved good teaching effect, and a large number of excellent robot works have emerged.

\subsection{Stimulate students' ability of invention and innovation}

The school's Robot Association organizes robot enthusiasts to carry out bold exploration and innovation of various types of robots; teachers guide students to actively participate in various robot related competitions. These exercise the students' innovative thinking, competition and innovation ability to promote. Many students' works, such as transformers robot, AGV robot, library robot and so on, won awards.

\subsection{Training students' engineering design thinking}

Many students take robot related topics as graduation design topics in their senior year graduation design. From literature comparison to machine design, and even to mechanical processing, students can independently complete a complete set of miniaturized robot design, which improves students' engineering design and application ability. 
Figure 1 shows some excellent works of student competition and graduation project.

\section{Conclusion}

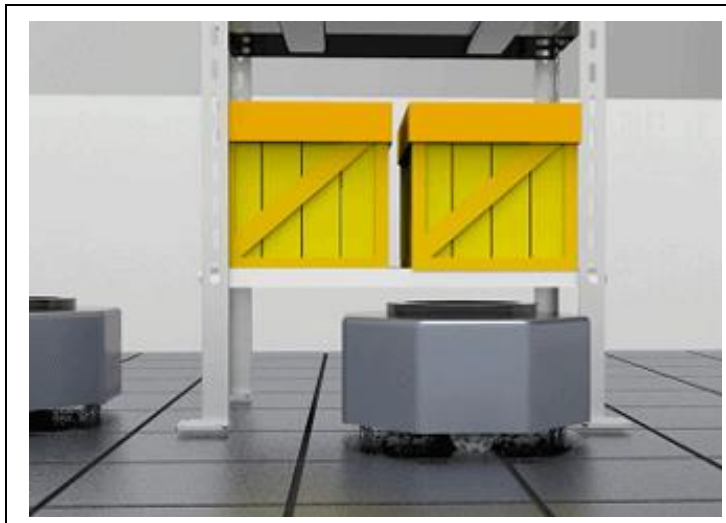

(a)AGV model of the 15th Challenge Cup, first prize of Guangdong Province

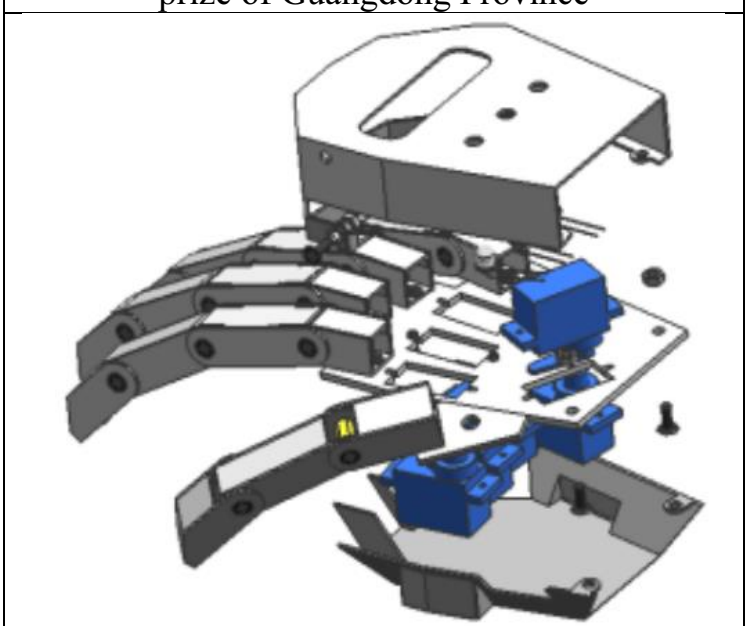

(c)Explosion diagram of bionic manipulator made by students in graduation project

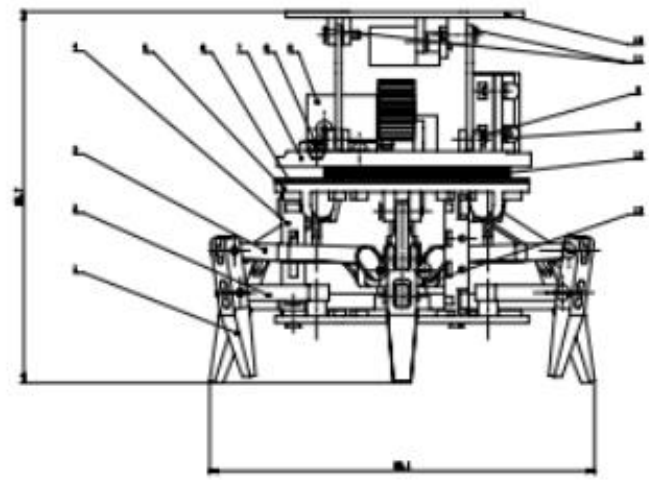

(e)Self made assembly drawing of electric hexapod robot for graduation project
The talent training in the direction of robot exerts the students' ability to collect, sort out and use their comprehensive knowledge, exercise their practical ability, and stimulate their innovative consciousness, which is in line with the training goal of compound applied talents. The teaching effect of robot related courses has laid a good foundation for further deepening the reform of the follow-up courses and improving the teaching quality.

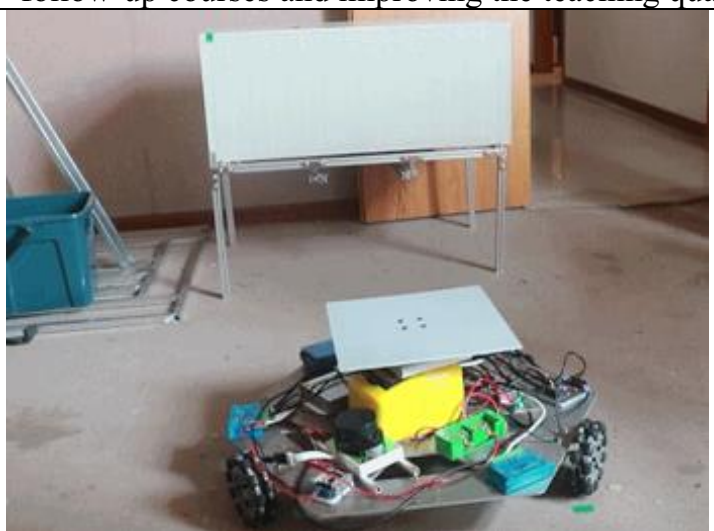

(b)AGV vehicle of the 15th Challenge Cup, first prize of Guangdong Province

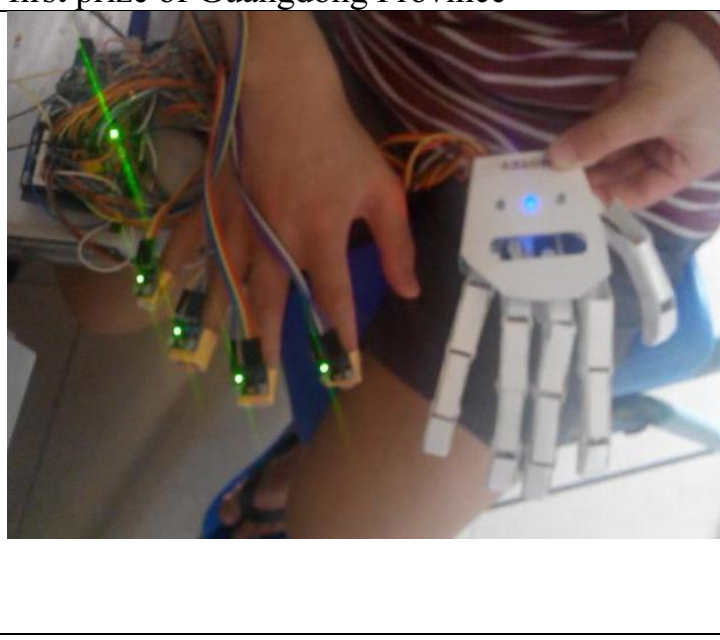

(d)self-made wearable manipulator in students' graduation design

\section{Figure 1. Some student works}




\section{Acknowledgments}

The authors would like to express their sincere thanks to the editor and the reviewers for their constructive suggestions, which are very important for the improvement of the paper quality. They also acknowledge the financial supports from teaching quality engineering project (Project No. ZLGC20180814, 2018010) and (Project No. ZLGC20200101) of Zhuhai College of Jilin University of China.

\section{References:}

1. Zhimin Mei, Yonglian Zhou, Jian Zhang, Fanglin Zhang , Youzuo Wang. (2019),Discussion on practice teaching reform of industrial robot specialty in Private Higher Vocational Education $[\mathrm{J}]$. Think Tank Era, (3) : pp227-228

2. He Li-le, Zheng Jian-xiao,( 2014), The Cultivatation of the Students' Practice and Innovation Ability Based on the Robot Teaching and Experiment Platform $[\mathrm{J}]$. Equipment Manufacturing Technology, (09): pp286-288

3. Wang Fang, Liu Kang, Li Jie, Zhou Zijian.(2020), Teaching exploration based on industrial robot technology $[\mathrm{J}]$. Computer products and circulation, (10) : pp37+78

4. Jianhai Han, Yanbin Liu, Xiangchen Ku.( 2013), Teaching reform and practice of "robotics" [ J ] . China Electric Power Education, (8)

5. $\mathrm{Xu}$ Hongying, $\mathrm{Li} \mathrm{Yi}$, Zhao Pengju.(2012)Training and practice of innovative talents based on Robot Competition $[\mathrm{J}]$.Exploration and Practice,pp245-246

6. Xianguo Cheng, Huiping Sun, Zhantao Li. ( 2015), Teaching Reform on Industrial Robot Technology Course [J] . Journal of Ningbo University of Technology, 27 (4) 